Abstracted/indexed in Academic Search Complete, Asia Journals Online, Bangladesh Journals Online, Biological Abstracts, BIOSIS Previews, CAB Abstracts, Current Abstracts, Directory of Open Access Journals, EMBASE/Excerpta Medica, Google Scholar, HINARI (WHO), International Pharmaceutical Abstracts, Open J-gate, Science Citation Index Expanded, SCOPUS and Social Sciences Citation Index;

ISSN: $1991-0088$

\title{
Hydroxysafflor yellow A suppresses oxidized low density lipoprotein induced proliferation of vascular smooth muscle cells
}

\author{
Lin Sheng, Shaojie Bi, Chao Cheng and Jingbo Zhang \\ Department of Cardiology, The 2nd Hospital of Shandong University, Jinan, Shandong 250033, China.
}

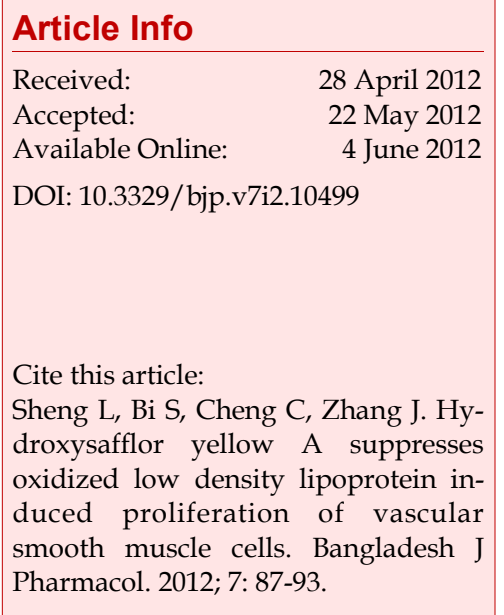

\section{Abstract}

To investigate the relationship between the suppression of hydroxysafflor yellow A (HSYA) on the oxidized low density lipoprotein (ox-LDL) induced proliferation of vascular smooth muscle cells (VSMCs) and the mRNA and protein expression of extracellular signal-regulated protein kinase 1/2 (ERK1/2) and mitogen activated protein kinase phospholipase-1 (MAKP-1), VSMCs were treated with HSYA at $10 \mu \mathrm{mol} / \mathrm{L}$ and/or ox-LDL at $35 \mathrm{mg} / \mathrm{L}$ for 48 hours. MTT assay was done to measure cell survival rate, flow cytometry to detect cell cycle, reverse transcription PCR and Western blot to detect the expression of ERK1/2 and MAKP-1. When compared to cells treated with oxLDL alone, the survival rate of cells treated with two reagents was reduced and the proportion of cells in $G_{0} / G_{1}$ phase significantly increased, with increased MKP-1 expression. The study suggests HSYA can inhibit VSMC proliferation via increasing MKP-1 expression, reducing p-ERK1/2 activity and suppressing cell cycle.

\section{Introduction}

Proliferation of vascular smooth muscle cells (VSMCs) is a shared pathological basis in atherosclerosis, hypertension and vascular restenosis after interventional treatment (Curcio et al., 2011). Oxidized low-density lipoproteins (ox-LDL) can cause damage to VSMCs, stimulate the proliferation of VSMCs and induce their apoptosis. This may reduce the stability of atheromatous plaques, and plays an important role in the occurrence and development of vascular lesions (Stoll and Bendszus, 2006; Imazu et al., 2008). In recent years, studies also demonstrated ox-LDL was closely related to the vascular restenosis after coronary interventional therapy (Naruko et al., 2006). Safflor yellow is an extract of safflower carthamus and a compound of multiple water-soluble chalcones. Safflor yellow has been regarded as a major effective component of safflower carthamus. Further purification of Safflor yellow can classify Safflower carthamus into hydroxysafflor yellow A (HSYA), HSYB and HSYC, of which HSYA is a major flavone with the highest proportion and also a main component exerting pharmacological effect of safflower carthamus. HSYA has been found to exert protective effect on myocardial ischemia, inhibit platelet aggregation, confer anti-thrombotic and anti-oxidative effect and relieve the angina. Thus, it has been widely applied in clinical practice. There is evidence showing that safflower carthamus can inhibit the proliferation of VSMCs (Wan et al., 2011), but the effect of safflower carthamus on the ox-LDL induced proliferation of VSMCs is still unclear.

In the present study, VSMCs were collected from rats and the effect of HSYA on ox-LDL induced proliferation of VSMCs and the potential mechanism were investigated. 


\section{Materials and Methods}

\section{Reagents and instruments}

HSYA (purity: 98\%; molecule formula: $\mathrm{C}_{27} \mathrm{H}_{32} \mathrm{O}_{16}$ ) was provided by the Modern Chinese Medicine Laboratory of the Center on Engineering Technology of Natural Medicine in Shandong Province. DMEM, trypsin (GIBCO), fetal bovine serum (Hangzhou Sijiqing Biotech Co., Ltd), monoclonal antibodies against phosphorylated extracellular signal-regulated kinase 1/2 (pERK1/2) and MAKP-1 (Cell Signal Technology, USA), $\beta$ -actin, HRP conjugated goat anti-rabbit IgG (Jingmei Biotech Co., Ltd); $\beta$-tubulin, HRP conjugated goat antirabbit IgG (Santa Cruz), PD98059 (Sigma-Aldrich), SuperSignal Western Pico Chemiluminescence Substrate (Pierce, USA), bovine serum albumin (BSA), promide iodine (PI) (Amerisco, USA), N, N, N, Ntetramethylethylenediamine (TEMED), ammonium persulfate (APS), RNase (Sigma, USA), Coomassie brilliant blue, acrylamide, methylene bisacrylamide (Bio Basic Inc. BBI, USA), absolute ethanol and ox-LDL (Beijing Xinyuan Jiahe Biotech Co., Ltd) were used in the present study. The main instruments included $\mathrm{CO}_{2}$ cell incubator (Forma Scientific, Inc. USA), fluorescence microscope (Olympus, Japan), ELISA Reader (Multiskan Mk3, Shanghai Leibo Analytical Instruments Co., Ltd.), flow cytometry (BD FACS Calibur), thermocycler (MT Research INC), DYY-III6 electrophoresis apparatus (Shanghai Medical Instrument Factory) and electrophoretic transfer (BioRad, USA).

\section{Cell culture}

Sprague Dawley (SD) rats were purchased from the Experimental Animal Center of the Second Hospital of Shangdong University (License Number: SYXK (Shangdong) 2005 0050). Thoracic aorta was collected from male rats weighing $150 \mathrm{~g}$ and the vascular adventitia was removed. Then, the vascular intima was collected and cut into pieces with $1 \times 1 \mathrm{~mm}$ in size which were then added into a flask followed by incubation at $37^{\circ} \mathrm{C}$ in an environment with $5 \% \mathrm{CO}_{2}$ in DMEM containing 20\% FBS. The medium was refreshed every 3 5 days. When the cell confluence reached $60 \sim 80 \%$, cells were digested with $0.25 \%$ trypsin followed by passaging which was done once every $4 \sim 6$ days. When the spindle like cells spread the flask, typical peak-valley like structure was present. The VSMCs of passage $3 \sim 8$ were used in the following experiments.

\section{Grouping}

On the basis of results in our pilot study, the optimal concentration of ox-LDL and HSYA was determined as $35 \mathrm{mg} / \mathrm{L}$ and $10 \mu \mathrm{mol} / \mathrm{L}$, respectively. The cells were divided into 5 groups. In the Group 1 (control group), cells were maintained in DMEM containing 0.5\% FBS; cells in the Group 2 were treated with ox-LDL at 35 $\mathrm{mg} / \mathrm{L}$; cells in the Group 3 were incubated with HSYA at $10 \mu \mathrm{mol} / \mathrm{L}$ and ox-LDL at $35 \mathrm{mg} / \mathrm{L}$; cells in the Group 4 were treated with PD98059 at $10 \mu \mathrm{mol} / \mathrm{L}$ and ox-LDL at $35 \mathrm{mg} / \mathrm{L}$; cells in the Group 5 were incubated with PD98059 at $10 \mu \mathrm{mol} / \mathrm{L}, \mathrm{HSYA}$ at $10 \mu \mathrm{mol} / \mathrm{L}$ and ox-LDL at $35 \mathrm{mg} / \mathrm{L}$. Incubation was done for 48 hours.

\section{Detection of cell survival by MTT assay}

Cells in logarthmic growth phase were washed in PBS and single cell suspension was prepared after digestion with $0.25 \%$ trypsin. These cells were seeded into 96well plate $(1 \times 103$ cells/well) followed by incubation at $37^{\circ} \mathrm{C}$ in an environment with $5 \% \mathrm{CO}_{2}$ for 24 hours. When cells were adherent to the wall, ox-LDL was added (6 wells in each group) followed incubation for another 24 hours. Then, cells were washed and incubated with $5 \mathrm{~g} / \mathrm{L}$ MTT $(20 \mu \mathrm{L})$ for 4 horus. The medium was removed and DMSO was added followed by detection with a microplate reader at $570 \mathrm{~nm}$. The absorbance (A) was recorded and the cell survival was calculated as follow: Atreatment/Acontrol $\times 100 \%$ (Brunt et al., 2006).

\section{Detection of cell cycle by flow cytometry}

The grouping and treatment were identical to those above. Cells were digested with $0.25 \%$ trypsin and single cell suspension was prepared followed by centrifugation at $4^{\circ} \mathrm{C}$ for $6 \mathrm{~min}$ at $2000 \times \mathrm{g}$. The supernatant was removed and cells were washed in PBS twice by centrifugation. The cells were then fixed in $0.5 \mathrm{~mL}$ of $70 \%$ pre-cooled ethanol at $4^{\circ} \mathrm{C}$ overnight. The cells were collected and centrifuged at $4^{\circ} \mathrm{C}$ for 6 $\min$ at $2000 \times \mathrm{g}$ to remove ethanol. After washing in precooled PBS twice, cells were centrifuged and then collected. Cells were mixed in $537 \mu \mathrm{L}$ of PBS and $3 \mu \mathrm{L}$ of RNase followed by incubation at $37^{\circ} \mathrm{C}$ for $30 \mathrm{~min}$. Then, $60 \mu \mathrm{L}$ of PI solution was added followed by incubation in dark for $30 \mathrm{~min}$. The mixture was transferred into another tube and subjected to flow cytometry. The cell cycle was measured.

\section{Detection of mRNA expression of MKP-1 and ERK1/2 by RT-PCR}

1) Extraction of total RNA: VSMCs were maintained in 24-well plate and treatment was abovementioned. The medium was removed and cells were treated with Trizol reagent for extraction of total RNA from VSMCs according to manufacturer's instructions. 2) Reverse transcription of RNA: $10 \mu \mathrm{L}$ of RNA was mixed with 0.2 $\mu \mathrm{L}$ of Oligo dT (500 mg/L), $2.5 \mu \mathrm{L}$ of dNTP $(10 \mathrm{mmol} /$ $\mathrm{L}), 0.5 \mu \mathrm{L}$ of $\mathrm{M}-\mathrm{MLV}$ reverse transcriptase (2 MU/L), 4 
Table I

\begin{tabular}{|c|c|c|}
\hline \multicolumn{3}{|c|}{$\begin{array}{c}\text { Effect of HSYA on ox-LDL induced proliferation of } \\
\text { VSMC in MTT assay }\end{array}$} \\
\hline Group & Cell survival (A) & Survival rate/\% \\
\hline Control group & $0.5 \pm 0.02$ & $100 \pm 0$ \\
\hline ox-LDL & $1.3 \pm 0.04^{a}$ & $277.8 \pm 15.2^{\mathrm{a}}$ \\
\hline HSYA+ox-LDL & $0.5 \pm 0.02^{b}$ & $110.3 \pm 9.7^{b}$ \\
\hline PD98059+ox-LDL & $0.5 \pm 0.02^{b}$ & $115.6 \pm 12.5^{b}$ \\
\hline $\begin{array}{l}\text { PD98059+HSYA } \\
+ \text { ox- LDL }\end{array}$ & $0.5 \pm 0.01^{b}$ & $106.4 \pm 11.1^{b}$ \\
\hline
\end{tabular}

Cells in different groups were incubated for 48 hours. ' $x \pm s, n=6$. ${ }^{a} \mathrm{p}<0.01$, vs control group; ${ }^{b} \mathrm{p}<0.01$, vs ox-LDL group

\section{Table II}

Effect of HSYA on cell cycle of ox-LDL treated VSMCs

\begin{tabular}{|lrr|}
\hline Group & $\mathrm{G}_{0} / \mathrm{G}_{1}(\%)$ & \multicolumn{1}{c}{$\mathrm{S} / \mathrm{G}_{2}-\mathrm{M}(\%)$} \\
\hline Normal control & $86.3 \pm 3.3$ & $13.7 \pm 2.5$ \\
ox-LDL & $59.7 \pm 3.1 \mathrm{a}$ & $40.3 \pm 3.9 \mathrm{a}$ \\
HSYA+ox-LDL & $79.8 \pm 9.5 \mathrm{~b}$ & $20.2 \pm 2.1 \mathrm{~b}$ \\
PD98059+ox-LDL & $75.0 \pm 8.3 \mathrm{c}$ & $25.0 \pm 4.2 \mathrm{c}$ \\
PD98059+HSYA+ox & $82.9 \pm 11.4 \mathrm{c}$ & $17.0 \pm 2.5 \mathrm{c}$ \\
-LDL & & \\
\hline
\end{tabular}

'x \pm s, $n=6$. ap $<0.01$, vs control group; $b p<0.05, c p<0.01$, vs ox-LDL group

$\mu \mathrm{L}$ of RT $(5 \times), 0.5 \mu \mathrm{L}$ of RNasin $(4 \mathrm{kU} / \mathrm{L})$ and water with the final volume of $20 \mu \mathrm{L}$. This mixture was incubated at $37^{\circ} \mathrm{C}$ for $30 \mathrm{~min}, 95^{\circ} \mathrm{C}$ for $10 \mathrm{~min}$ and then $0^{\circ} \mathrm{C}$ for $5 \mathrm{~min}$. The mixture was stored at $-20^{\circ} \mathrm{C}$ for use. 3) Amplification with PCR: the products $(5 \mu L)$ from reverse transcription served as template and mixed with $0.5 \mu \mathrm{L}$ of forward primer $(50 \mathrm{mmol} / \mathrm{L}), 0.5 \mu \mathrm{L}$ of reverse primer $(50 \mathrm{mmol} / \mathrm{L}), 1 \mu \mathrm{L}$ of $\mathrm{dNTP}(10 \mathrm{mmol} /$ $\mathrm{L}), 0.5 \mu \mathrm{L}$ of Taq polymerase $(5 \mathrm{kU} / \mathrm{L}), 5 \mu \mathrm{L}$ of PCR buffer $(10 \times), 5 \mu \mathrm{L}$ of $\mathrm{MgCl}_{2}(25 \mathrm{mmol} / \mathrm{L})$ and water with the final volume of $50 \mu \mathrm{L}$. Amplification was done in a thermocycler. Predenaturation was done at $95^{\circ} \mathrm{C}$, followed by 30 cycles of denaturation at $91.6^{\circ} \mathrm{C}$ for $45 \mathrm{~s}$, annealing at $57^{\circ} \mathrm{C}$ for $60 \mathrm{~s}$, and $72^{\circ} \mathrm{C}$ for $60 \mathrm{~s}$, and a final extension was also performed at $72^{\circ} \mathrm{C}$ for $5 \mathrm{~min}$. The primers were as follows: MAKP-1: $5^{\prime}$ - TCTGGATTGTCGCTCCTTCT-3' (forward), 5'- GTCTGCCTTGTGGTTGTCC T-3' (reverse), the anticipated size was 619 bp; ERK1/2: 5'-ACAC A T GC T T T GG G T C C T T C-3 ' (f o r w a r d ), 5' - AGGAACAGCTCACAGCCCTA3' (reverse), the anticipated size was 883 bp; GAPDH: 5'- CATCACCATCTTCCAGGAGCA-3' (forward), 5' TGACCTTGCCCACAGCCTTG-3' (reverse), the anticipated size was $443 \mathrm{bp}$. The products were subjected to agarose gel electrophoresis and Furi FR- 980A image analysis system was employed to detect the integrated absorbance (IA) of each band. The mRNA expression of target genes was normalized by that of GAPDH as the relative expression of target genes.

\section{Detection of protein expression of ERK1/2 and MAKP-1 by Western blot}

Cells in logarithmic growth phase were seeded into 6well plate at a density of $1 \times 108$ cells/L followed by incubation at $37^{\circ} \mathrm{C}$ in an environment with $5 \% \mathrm{CO}_{2}$. When cell confluence reached $90 \%$, the cells were collected and washed with cold PBS thrice. The cells were then mixed with lysis buffer on ice followed by centrifugation at $14000 \times \mathrm{g}$ for $15 \mathrm{~min}$. The supernatant was removed and protein concentration was determined with a BCA protein kit. Then, $40 \mu \mathrm{g}$ of proteins in each group was loaded and subjected to $10 \%$ SDS-PAGE (stack gel: $80 \mathrm{mV}$; separation gel: $120 \mathrm{mV}$ ). The proteins were transferred onto PVDF membrane at $150 \mathrm{~mA}$ for 1.5 hours). Ponceau staining was employed to detect the protein transferring. Then, the membrane was blocked in 5\% non-fat milk for 1 hours and treated with rabbit anti-MAKP-1 (1:1000) or ERK1/2 (1:1000) antibodies at $4^{\circ} \mathrm{C}$ overnight. After washing in TBST, the membrane was incubated with secondary antibody (1:5000) at room temperature for 1 hour and visualization was done with ECL kit. GIS image analysis system was employed to detect the protein expression. The expression of target proteins was normalized by that of reference.

\section{Statistical analysis}

Data were expressed as mean \pm standard deviation $(x \pm$ s). Quantitative data were compared with t-test and qualitative data with Chi-square test. A value of $\mathrm{p}<0.05$ was considered statistically significant.

\section{Results}

As shown in Table I, when compared with Group 1, the survival rate of ox-LDL treated VSMCs was markedly increased (277.8\%). However, after incubation with oxLDL and HSYA, the cell proliferation was significantly inhibited and the survival rate was reduced by $60.3 \%$ $(p<0.01)$. Cells treated with PD98059 (an inhibitor of ERK1/2) and oxLDL presented significantly inhibited proliferation and the survival rate was reduced by $58.4 \%$ ( $\mathrm{p}<0.01)$. The incubation with HSYA, PD98059 and ox-LDL further suppressed the cell growth and the survival rate was reduced by $61.7 \%$ when compared with control group $(\mathrm{p}<0.01)$, but it was comparable to that of cells treated with HSYA+ox-LDL or PD98059+ox -LDL ( $p>0.05)$. 


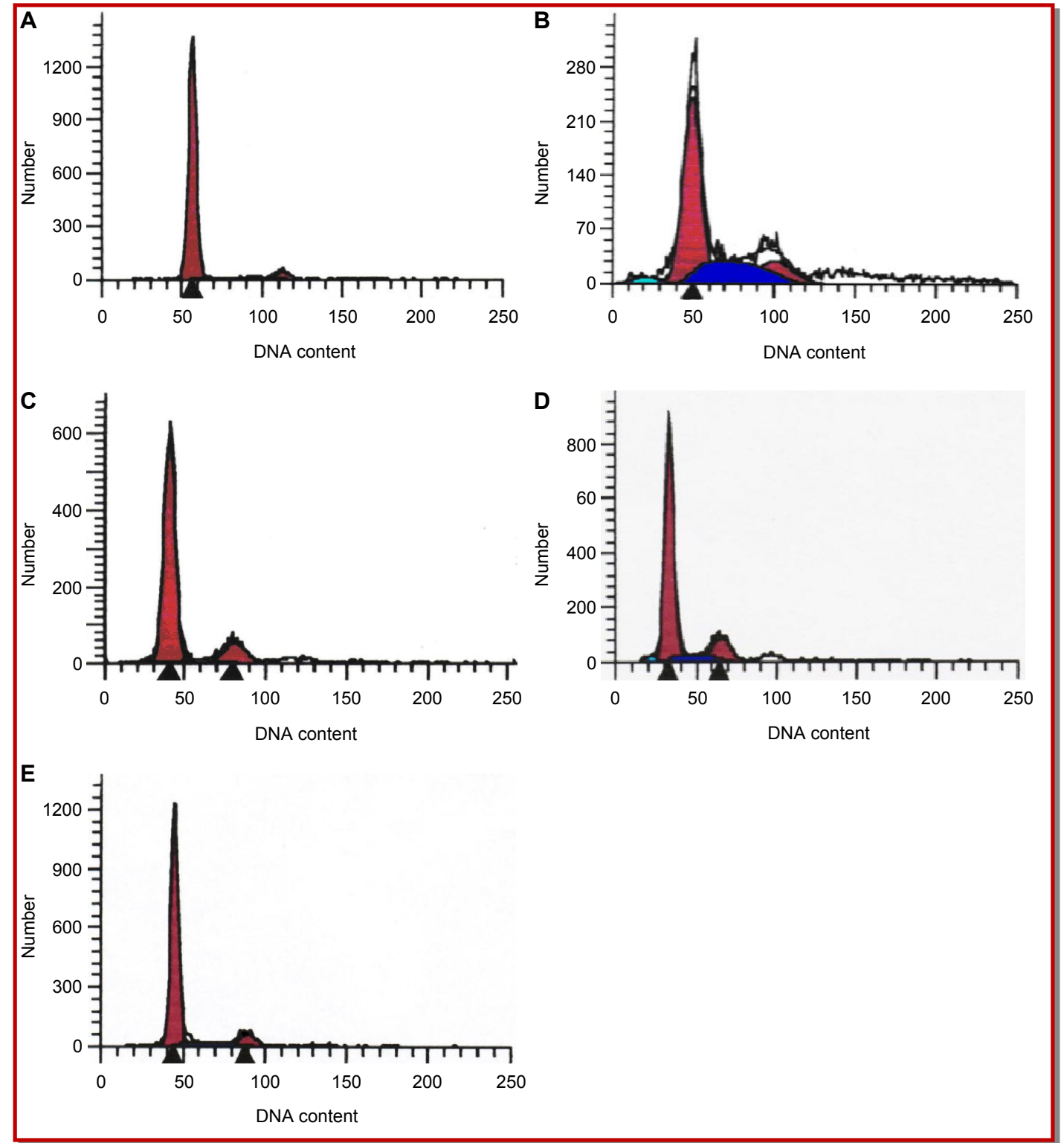

Figure 1: Effects of HSYA on cell cycle in ox-LDL treated VSMCs

VSMCs were treated with ox-LDL, HSYA+ox-LDL, PD98059+ox-LDL and PD98059+ HSYA +ox-LDL for 48 h. Cell cycle was determined by flow cytometry. A: control;B: 35 mg/L ox-LDL; C: 10 mmol/L ox-LDL + 35 mg/L HSYA; D: 10 mol/L PD98059

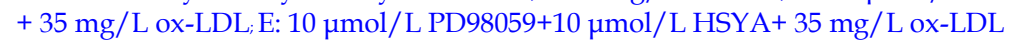

Flow cytometry showed the ox-LDL could promote the progression of cell cycle, the proportion of cells in $\mathrm{G}_{0}$ / $\mathrm{G}_{1}$ phase was reduced by $26.6 \%$ and that in $S$ phase was markedly increased $(p<0.01)$. After treatment with HSYA for 48 hours, the HSYA significantly inhibited the ox-LDL induced promotion of cell cycle and $79.8 \%$ of VSMCs was arrested in $\mathrm{G}_{0} / \mathrm{G}_{1}$ phase $(\mathrm{p}<0.05)$. Following treatment with PD98059 and ox-LDL, the cell cycle was also arrested and $75.0 \%$ of VSMCs was arrested in $\mathrm{G}_{0} / \mathrm{G}_{1}$ phase $(\mathrm{p}<0.05)$. In cells treated with PD98059, HSYA and ox-LDL, the cell cycle progression was further inhibited, and the proportion of cells in $\mathrm{G}_{0}$ / $\mathrm{G}_{1}$ phase was dramatically reduced when compared with control group, but was comparable to that in HSYA+ox-LDL group and PD98059+ox-LDL group (Figure 1A E; Table II).

In the ox-LDL group, the mRNA expression of ERK1/2 in VSMCs was markedly higher than that in the control group (2.2-fold; $0.907 \pm 0.087$ vs $0.287 \pm 0.017)(p<0.01)$, but the mRNA expression of MAKP-1 was slightly increased $(p>0.05)$. In the ox-LDL+HSYA group, the 


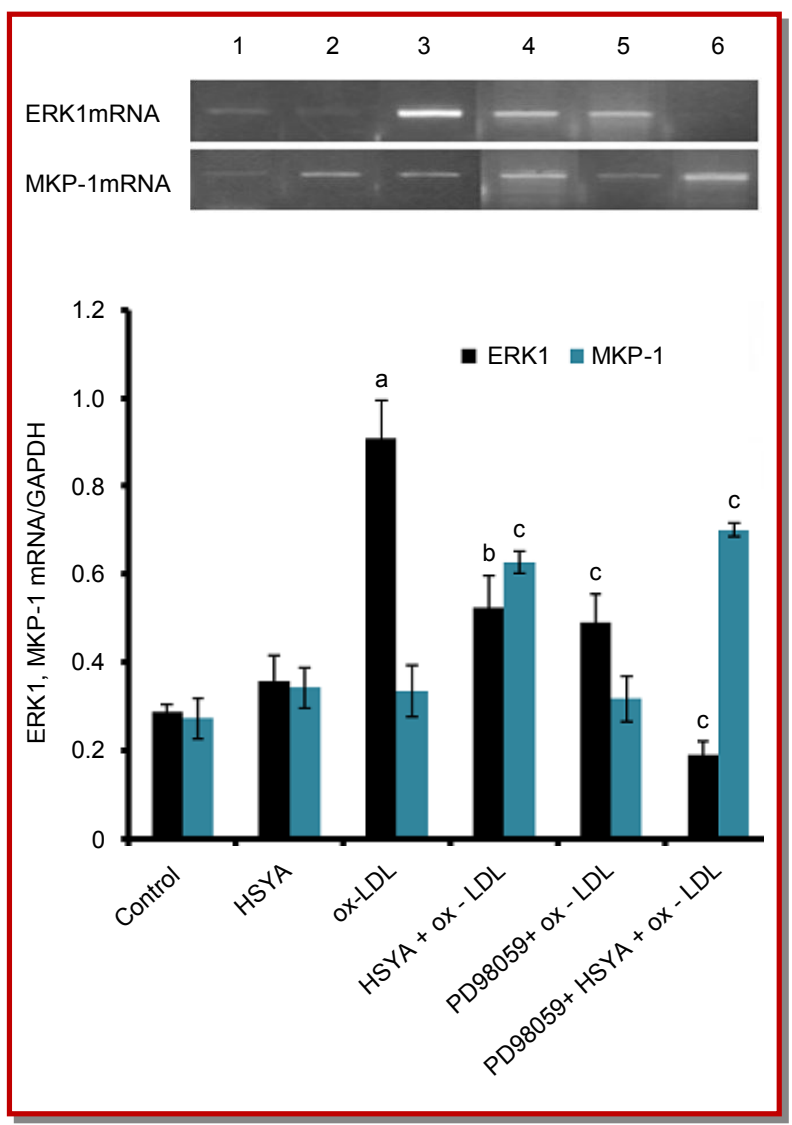

Figure 2: Effects of HSYA on the mRNA expression of ERK ${ }_{1}$ and MAKP-1 in VSMCs in the presence of ox-LDL. Cells were treated with ox-LDL, HSYA+ox-LDL, PD98059+ox-LDL and PD98059+HSYA+ox-LDL for 48 hours. mRNA expression of ERK1/2 and MKP- 1 in VSMCs was determined by RT-PCR. A. 1. Control; 2. HSYA; 3. ox-LDL; 4. HSYA+ox-LDL; 5. PD98059+ox-LDL; 6. D98059+HSYA+ox-LDL. B.

- mRNA expression of target genes was normalized by that of X GAPDH. $\pm s, \mathrm{n}=6$; ${ }^{\mathrm{a}} \mathrm{p}<0.01$, vs control group; ${ }^{\mathrm{p}} \mathrm{p}<0.05, \mathrm{c}<<0.01$ vs oxLDL group; $\mathbf{\Lambda}<<0.01$, vs PD98059+ox-LDL group

NA expression of ERK1/2 was significantly reduced by $42.2 \%(0.524 \pm 0.072$ vs $0.907 \pm 0.087 ; \mathrm{p}<0.01)$ and that of MAKP-1 markedly increased by $86.9 \%(0.628 \pm 0.025$ vs $0.336 \pm 0.059 ; \mathrm{p}<0.01)$. In the PD98059+ox-LDL group, the mRNA expression of ERK1/2 was reduced by $45.9 \%$ when compared with ox-LDL group but that of MAKP-1 remained unchanged. In the PD98059 + oxLDL + HSYA group, the mRNA expression of ERK1/2 was reduced by $79.1 \%$ when compared with ox-LDL group $(p<0.01)$ and that of MAKP-1 increase by $110 \%$. When compared with PD98059+ox-LDL group, the mRNA expression of ERK1/2 was reduced by $61.3 \%$ $(p<0.01)$ and that of MAKP-1 increased by $120 \%$ $(\mathrm{p}<0.01)$ in the PD98059 + ox-LDL + HSYA group (Figure 2).

In the ox-LDL group, the $\mathrm{p}-\mathrm{ERK} 1 / 2$ protein expression was markedly increased by $33.3 \%$ (1.954 \pm 0.075 vs 1.466 $\pm 0.086, \mathrm{p}<0.01$ ), but the MAKP-1 protein expression was slightly reduced by $7.4 \%$ when compared with control group $(\mathrm{p}>0.05)$. In the HSYA + oxLDL group, the p-ERK1/2 protein expression was markedly reduced by $39.9 \%(1.174 \pm 0.049$ vs $1.954 \pm 0.075 ; p<0.01)$ and that of MAKP-1 dramatically increased by $80.6 \%$ $(1.586 \pm 0.044$ vs $0.878 \pm 0.028, p<0.01)$. In the oxLDL + PD98059 group, the $\mathrm{p}-\mathrm{ERK} 1 / 2$ protein expression was significantly reduced by $45.9 \%$ when compared with ox-LDL group $(\mathrm{p}<0.01)$, but the MAKP-1 expression remains unchanged. In the PD98059 + HSYA + ox-LDL group, the MAKP-1 protein expression was increased by $62.4 \%(p<0.01)$ and that of $p$-ERK $1 / 2$ reduced by $51.2 \%(\mathrm{p}<0.01)$ when compared with oxLDL group. As compared to PD98059 + ox-LDL, the MAKP-1 protein expression was increased by $34.2 \%$ $(p<0.05)$ and that of $p$-ERK1/2 reduced slightly $(p>0.05)$ in the PD98059+HSYA + ox-LDL group (Figure 3).

\section{Discussion}

Our results showed ox-LDL at $35 \mathrm{mg} / \mathrm{L}$ could significantly increase the mRNA and protein expression of ERK1/2, promote cell cycle progression and stimulate the proliferation of VSMCs. HSYA at 10 $\mu \mathrm{mol} / \mathrm{L}$ could markedly increase the mRNA and protein expression of MKP-1, inhibit the p-ERK1/2 activity and inhibit the ox-LDL induced proliferation of VSMCs via arresting cells in $\mathrm{G}_{0} / \mathrm{G}_{1}$ phase. After treatment with a selective inhibitor of ERK1/2 (PD98059), the ox-LDL induced ERK1/2 expression and VSMC proliferation were dramatically inhibited, but the MAKP-1 expression remained unchanged. This further demonstrated that the ox-LDL induced proliferation of VSMCs depended on ERK1/2 signaling pathway but not the MAKP-1 pathway. In addition, following incubation with HSYA, PD98059 and ox-LDL, the MAKP-1 mRNA and protein expressions were markedly increased.

ERK1/2 is an important protein kinase regulating cell growth. Some stimulators including growth factors, angiotensin II and endothelin, etc have been found to promote the proliferation of VSMCs via ERK signaling pathway (Li et al., 2010; Xiang et al., 2010). MAKP-1 is a protein negatively regulating ERK1/2. MAKP-1 can inactivate ERK1/2 via dephosphorylating ERK1/2. Thus, to regulate the expression of ERK1/2 and/or MAKP-1 may influence the proliferation of VSMCs. The biological effect of ox-LDL on VSMCs is related to the ox-LDL concentration. ox-LDL at low concentration may stimulate the cell proliferation and induce apoptosis. Studies have demonstrated that ox-LDL can 


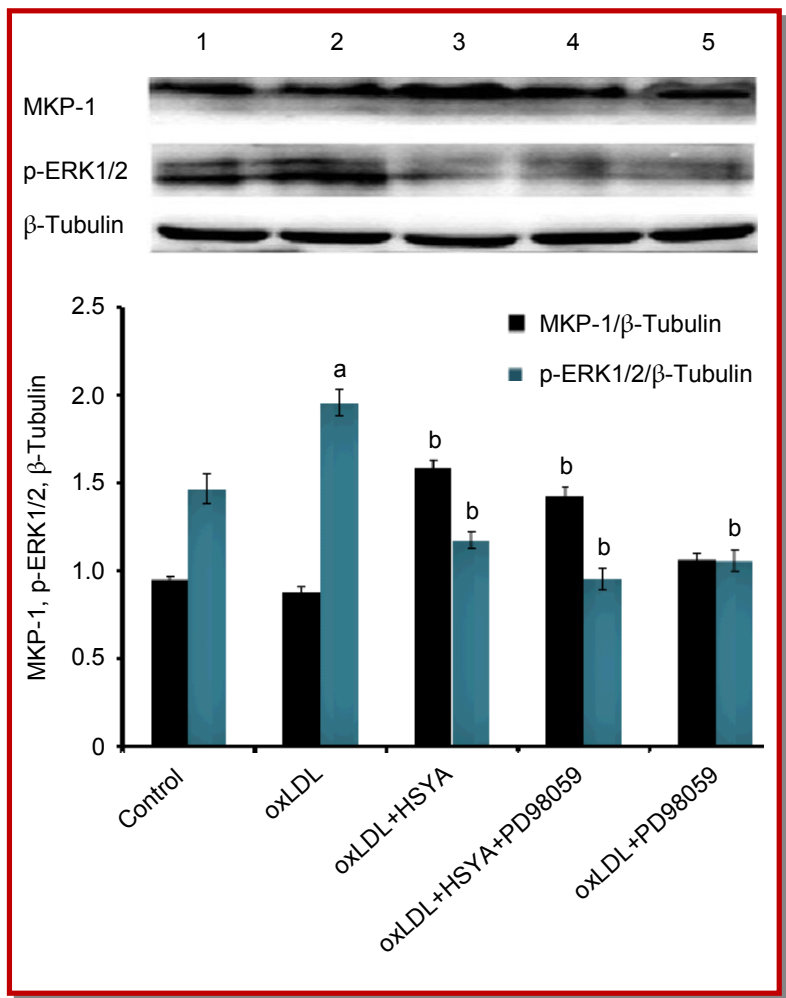

Figure 3: Effects of HSYA on the protein expression of $\mathrm{p}$ ERK1/2 and MKP-1 in VSMCs in the presence of ox-LDL. Cells were treat- ed with ox-LDL, HSYA+ox-LDL, PD98059+ox-LDL and PD98059+HSYA+ox-LDL for 48 hours. Protein expression of p-ERK1/2 and MAKP-1 in the medi- um was evaluated by Western blot assay. A: 1: Control; 2: $35 \mathrm{mg} / \mathrm{L}$ ox-LDL; 3: 10 $\mu \mathrm{mo} / \mathrm{LHSYA}+35 \mathrm{mg} / \mathrm{L}$ ox-LDL; $4: 10 \mu \mathrm{mol} / \mathrm{L}$ PD98059+10 $\mu \mathrm{mol} / \mathrm{L}$ HSYA+35 mg/L ox-LDL; 5: $10 \mu \mathrm{mol} / \mathrm{L}$ PD98059+35 $\mathrm{mg} / \mathrm{L}$ ox-LDL . B. Expression of target protein was normalized by that of $\beta$-Tubulin $\pm s, \mathrm{n}=6$; a $\mathrm{p}<0.01$, vs $\bar{X}$ control group; ${ }^{b} \mathrm{p}<0.01$, vs ox-LDL group; ${ }^{\circ} \mathrm{C} p<0.05$, vs oxLDL+PD98059 group

stimulate VSMC proliferation via activating Ras/Raf/ Mitogen-activated protein kinase kinase kinase (MEK)/ ERK1/2 signaling pathway and inducing Cyclin D expression (Perez et al., 2011; Yang et al., 2000; Watanabe et al., 2006; Chahine et al., 2009; Tu et al., 2005). Our results showed ox-LDL significantly increase the mRNA expression of ERK1/2 and protein expression of phosphorylated ERK1/2 (activated form of ERK1/2), which the promoted the progression of $\mathrm{G}_{0}$ / $\mathrm{G}_{1}$ phase into $\mathrm{S} / \mathrm{G}_{2}-\mathrm{M}$ phase. This further demonstrates that ERK1/2 activation involves in the ox-LDL induced VSMC proliferation. MAKP-1 is a protein negatively regulating ERK1/2. However, the relationship between ox-LDL induced cell proliferation and MAKP-1 expression and whether suppression of ox-LDL induced cell proliferation by HSYA may affect the MAKP-1 expression are largely unclear. In our study, results showed ox-LDL activated ERK1/2 but had no influence on the mRNA and protein expression of MAKP-1. Thus, ox-LDL induced VSMC proliferation is not associated with MAKP-1, but is directly related to the increase in mRNA expression of ERK1/2 and protein expression of $\mathrm{p}$-ERK1/2.

In addition, our results also demonstrated the PD98059, an ERK1/2 inhibitor, could inhibit the ox-LDL induced VSMC proliferation via reducing ERK1/2 transcription and p-ERK1/2 expression, but it had no effect on the mRNA and protein expression of MAKP-1. Different from PD98059, HSYA not only significantly reduced the p-ERK1/2 activity but markedly increase the mRNA and protein expression of MAKP-1. Thus, HSYA induced suppression of cell proliferation may result from increased MAKP-1 expression, reduced activities of p-ERK1/2 and its downstream Cyclin D1 and the inhibition of progression of $\mathrm{G}_{0} / \mathrm{G}_{1}$ into $\mathrm{S} / \mathrm{G}_{2}-\mathrm{M}$ phase. This may be an important mechanism underlying the HSYA related suppression of ox-LDL induced VSMC proliferation.

\section{Acknowledgement}

The study was supported by the Program from Shandong Administration of Traditional Chinese Medicine (2009163).

\section{References}

Brunt KR, Fenrich KK, Kiani G, Tse MY, Pang SC, Ward CA, Melo LG. Protection of human vascular smooth muscle cells from $\mathrm{H}_{2} \mathrm{O}_{2}$-induced apoptosis through functional codependence between HO-1 and AKT. Arterioscler Thromb Vasc Biol. 2006; 26: 2027-34.

Chahine MN, Blackwood DP, Dibrov E, Richard MN, Pierce GN. Oxidized LDL affects smooth muscle cell growth through MAPK-mediated actions on nuclear protein import. J Mol Cell Cardiol. 2009; 46: 431-41.

Curcio A, Torella D, Indolfi C. Mechanisms of smooth muscle cell proliferation and endothelial regeneration after vascular injury and stenting. Circ J. 2011; 75: 1287-96.

Imazu M, Ono K, Tadehara F, Kajiwara K, Yamamoto H, Sumii K, Tasaki N, Oiwa J, Shimohara Y, Gomyo Y, Itabe H. Plasma levels of oxidized low density lipoprotein are associated with stable angina pectoris and modalities of acute coronary syndrome. Int Heart J. 2008; 49: 515-24.

Li Y, Lévesque LO, Anand-Srivastava MB. Epidermal growth factor receptor transactivation by endogenous vasoactive peptides contributes to hyperproliferation of vascular smooth muscle cells of SHR. Am J Physiol Heart Circ Physiol. 2010; 299: H1959-67.

Naruko T, Ueda M, Ehara S, Itoh A, Haze K, Shirai N, Ikura Y, Ohsawa M, Itabe H, Kobayashi Y, Yamagishi H, Yoshiyama 
M, Yoshikawa J, Becker AE. Persistent high levels of plasma oxidized low-density lipoprotein after acute myocardial infarction predict stent restenosis. Arterioscler Thromb Vasc Biol. 2006; 26: 877-83.
Perez J, Torres RA, Rocic P, Cismowski MJ, Weber DS, DarleyUsmar VM, Lucchesi PA. PYK2 signaling is required for PDGF-dependent vascular smooth muscle cell proliferation. Am J Physiol Cell Physiol. 2011; 301: C242-51.

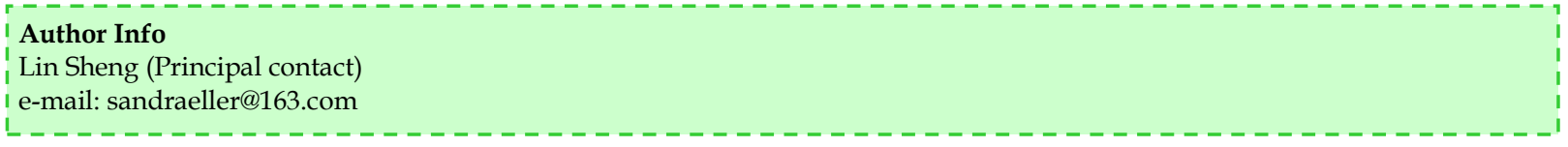

